\title{
Infant mortality and famine: a study in historical epidemiology in northern England
}

\author{
Susan Scott, S R Duncan, C J Duncan
}

\begin{abstract}
Objective - To examine whether periodic variations in annual infant mortality were associated with malnutrition and the poor quality of the food supply available to the community.
\end{abstract}

Design - Retrospective study of historical epidemiology of infant mortality by time series analysis and family reconstitution of parish registers of burials and baptisms. Setting - Penrith, Cumbria, England, 1557-1812.

Subjects - A total of 17500 births during 1557-1812.

Results - This community in the Eden Valley, Cumbria, close to the Scottish borders, was living under marginal conditions with high mortality and low fertility. Clear oscillations in infant mortality synchronise with the oscillations in the wheat price index which is regarded as a measure of the availability of food to the community, and to pregnant and nursing mothers in particular. Input-output analysis showed that the relationship between the wheat price index (input) and infant mortality (output) was highly significant $(p<0 \cdot 001)$. Events during the famine of 1623 have been analysed in detail: high wheat prices during pregnancy caused subsequent severe infant mortality but did not have indirect effects on the subsequent mortality of the surviving children over the age of 1 year. Non-stationary oscillations in neonatal and post neonatal mortality were strongly coherent $(p<0.001)$ with the wheat price index throughout the period. Conclusions - Infant mortality is particularly sensitive to famine and also to the quality of the food supply available to pregnant and nursing mothers. The lags between neonatal and post-neonatal mortalities and wheat prices, together with the analysis of the famine of 1623 , support the hypothesis that neonatal mortality was related to malnutrition in pregnancy whereas post-neonatal mortality was primarily directly dependent on exogenous causes in the first year of life.

( $\mathcal{F}$ Epidemiol Community Health 1995;49:245-252)

Barker et $a l^{1}$ have shown by their studies in historical epidemiology that nutrition during pregnancy and infancy is of critical importance for growth and development and also for the subsequent health of the adult. ${ }^{2} \mathrm{~A}$ high neonatal mortality and a high incidence of low birth weight are directly associated with poor maternal nutrition. ${ }^{3}$ Neonatal mortality in the past was high in places where babies were born with low weight and is also known to have been associated with high maternal mortality. High rates for both neonatal and maternal mortality were found in places where the physique and health of women were poor. ${ }^{4}$ It is fundamental to geographical studies that infant deaths are indicators of adverse circumstances. ${ }^{5}$ Infant mortality is subdivided into neonatal mortality (deaths in the first 28 days after birth) and postneonatal mortality (deaths between 28 days and 1 year). Neonatal deaths are strongly dependent on problems that occur during pregnancy, birth, and the period immediately after birth, whereas post-neonatal deaths are particularly dependent on environmental factors in infancy. It is also the thesis of Barker that not only did malnutrition in pregnancy result in high infant mortality but that the subsequent health of the adults was also impaired. ${ }^{1}$

Many of these epidemiological studies have been based on the valuable and detailed statistics of births in Hertfordshire, 1911-1930, when birth weights and weights at 1 year were recorded. These data for male children have been compared with their subsequent medical history and with the incidence of ischaemic heart disease and impaired glucose tolerance among the survivors today. No comparable quantitative data exist for epidemiological studies in the 17th and 18th centuries. However, we have shown ${ }^{6}$ that parish baptisms and burials records, where complete over a long period, represent a valuable source of data for theoretical population biologists, wherein oscillations in births and deaths can be detected by conventional time series analysis. These records can also be used to identify smallpox epidemics in rural towns and to analyse their regular periodicity. ${ }^{7}$ These five-yearly smallpox epidemics are in marked contrast to the twoyearly epidemics in large cities that have been shown by time-series analysis. ${ }^{89}$

Infant mortality (rather than childhood mortality) is believed to be the most sensitive to the effects of malnutrition (Barker, personal communication) and we present here the results of a study of the parish of Penrith, Cumbria between 1557 and 1812. Situated in the Eden valley, close to the Scottish borders, the conditions at Penrith during the 17th and 18th centuries were severe ${ }^{1011}$; much of the Northern Provinces were remote from large trading centres, and seen through the eyes of southerners, this was a wild and savage country, its inhabitants without understanding of a lawabiding society and harbouring a characteristic 
frontier society. ${ }^{12}$ The main hazard was the meagre corn harvest, the crops being bigg (a poor variety of barley) and oats. Even as late as 1790, a Cumberland correspondent wrote "At the beginning of this century, the inhabitants were in a state bordering on extreme indigence and ignorance ... they lived barely on the product of their little farms". ${ }^{13}$ In addition, the landlords gradually increased the entry fines demanded of their tenants during the 16th century, and "the miserable tenant, who is going to pay an arbitrary fine and a heriot, is perpetually impoverished ... those customary tenures are a national grievance. From this tenure is chiefly to be attributed the vast and dreary wastes that are found in Cumberland". ${ }^{14}$ Conditions had not improved by 1800: "There are probably few counties, where property in land is divided into such small parcels as in Cumberland; and those small properties so universally occupied by the owner; by far the greatest part of which are held under the lords of the manor, by a species of vassalage, called customary tenure; subject to the payment of fines and heriots, on alienation, death of the lord or death of tenant". ${ }^{15}$

\section{Subjects and methods}

The data were extracted from the published records of the parish of Penrith, Cumbria. ${ }^{16}$ Family reconstitution over the period 15571812 was carried out by the methods described by Wrigley ${ }^{17}$ and, in brief, this is a technique in which individual families are identified from the marriage register, and the births and deaths of each member of the family are traced from the baptism and burial registers.

Time series analysis is a useful, computer based tool for historical epidemiologists and can be applied to runs of data to extract the underlying oscillations, even if they display considerable noise. Spectral analysis is a computer programme that identifies the major wavelengths of the oscillations contained within such a data series, and appropriate filters can then be designed to eliminate trends, noise, and other oscillations. The resulting cycles, revealed after filtering, can be printed out and the wavelength(s) determined by an auto-correlation function programme. Stationary oscillations maintain a constant periodicity over the period of study, whereas non-stationary oscillations (more usually found in exogenously driven biological populations) are more variable, changing, for example, from five to six, or even seven year periodicity. A cross correlation function programme allows the direct comparison and the temporal relationships of two filtered series. A coherence programme is of particular value because it measures the significance of the input-output relationship in specific wavebands between two unfiltered data series. It will be shown, for example, that the non-stationary oscillations in wheat prices are strongly coherent with infant mortality in the short wavebands $(p<0.001)$ but there is no significant coherence (correlation) in other wavebands. These time-series functions were carried out by the method of Shumway. ${ }^{18}$

\section{Results}

DENSITY DEPENDENT CONDITIONS BETWEEN

1557 AND 1750

The population at Penrith remained in steady state for nearly 200 years (1557-1750); in spite of complex oscillations, the annual mean number of births and deaths remained remarkably constant (slopes $=0.0047$ and -0.024 respectively).$^{6}$ These steady state conditions were maintained by a feedback system involving differential mortality and migratory movements ${ }^{19}$ governed by the severe conditions at that time. Penrith suffered from the plague in 1597-98, when about $40 \%$ died. Conditions improved after 1750 and the population came out of steady state with a progressive increase in births and deaths. ${ }^{6}$

Thus, during the period after the plague (1600-1750) the calculated survival curves for females at Penrith ${ }^{20}$ show that mortality was severe, and during the early part of this period life expectancy at birth was estimated to be 27 years. Infant mortality was particularly high.

Age specific marital fertility at Penrith $(1600-1750)^{20}$ was considerably below the mean results previously obtained from 13 parishes over the same period. ${ }^{21}$ Fertility was particularly low for women aged under 25 years. ${ }^{22}$ Data on nutrition, growth, and age specific fertility rates suggest that a slow growth to maturity because of undernutrition is correlated with a reproductive span that is both shorter and less efficient than for a population with a balanced nutrition. ${ }^{23}$

\section{RELATIONSHIP BETWEEN INFANT MORTALITY} AND WHEAT PRICES

Annual infant mortality has been determined from the family reconstitution study and expressed as a percentage of births in that year. Spectral analysis of this data series shows a non-stationary, short wavelength oscillation, the period of which fluctuates from 4 to 10 years. This oscillation has been studied during the period of major famine conditions, 1557-

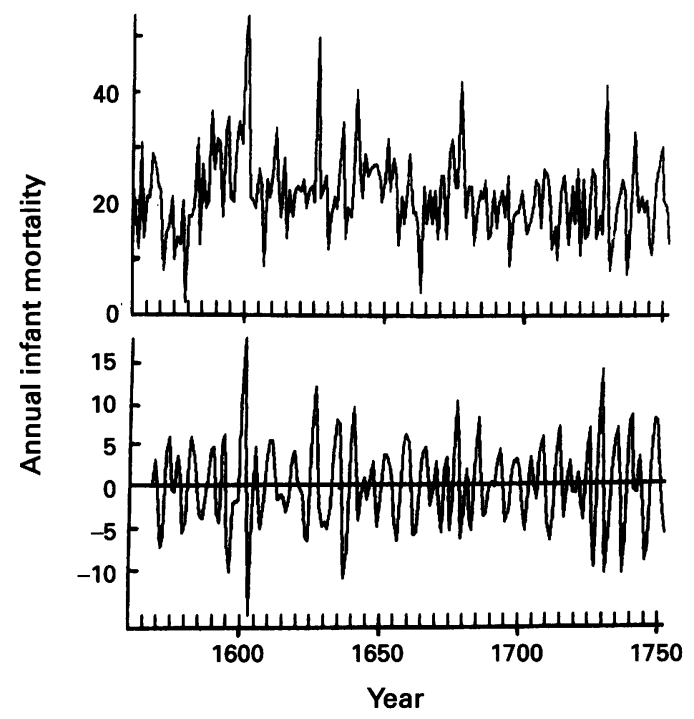

Figure 1 Annual infant mortality, 1557-1750, expressed as a percentage of births in that year, before (above) and after filtering (below). Filter window $=3.4$ to 10.6 years. 


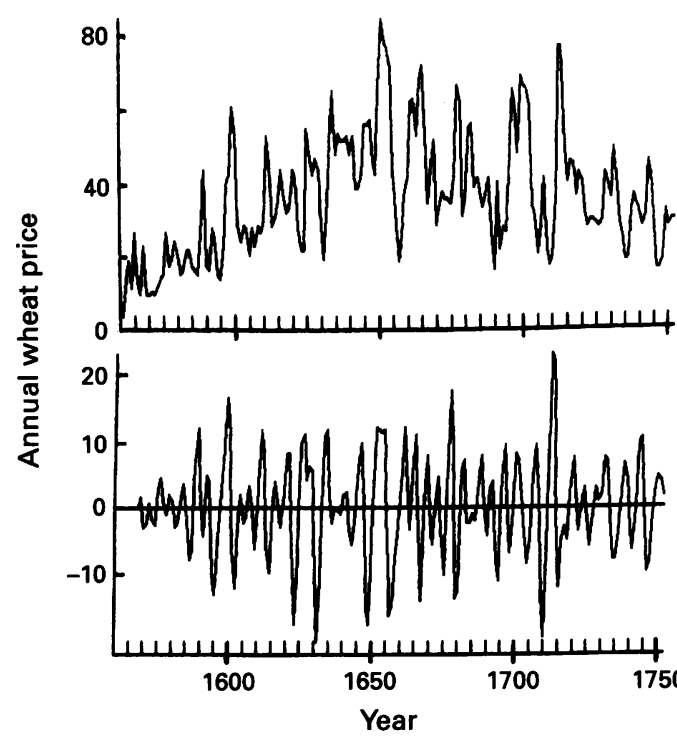

Figure 2 Annual wheat price index (shillings per quarter), 1557-1750, before (above) and after filtering (below). Filter window $=3.4$ to $10 \cdot 6$ years.

1750, when the community was in steady state $^{61011}$ and is shown unfiltered and after filtering in figure 1 (filter window $=3.4$ to 10.6 years wavelength). We suggest that this complex fluctuation in infant mortality is driven by periods of famine and malnutrition to which this population was particularly susceptible. ${ }^{6}$

One quantitative measure of famine is the annual index of wheat prices, which fluctuated appreciably. ${ }^{24}$ This index was applicable to the UK as a whole, although the main crop at Penrith in the 17th century was bigg, as shown by a study of the inventories and wills at that time. However, we have studied the annual index of barley prices and find that it cross correlates well with the wheat price index at zero lag. Both the wheat and barley price indices show strong negative cross correlation with the real wage index - that is, grain price oscillations are exactly out of phase with wages thereby exacerbating the hardship to the poorer famil-

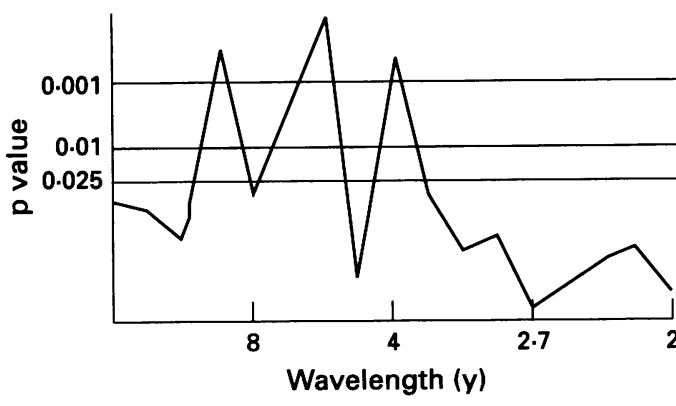

Figure 3 Coherence between wheat price index (input) and infant mortality expressed as a percentage of baptism (output) for the period 1557-1656. Ordinate: levels for the different values of $p$. Abscissa: wavelengths (years).

ies. We conclude that the wheat price index represents a useful measure of fluctuating famine and hardship. Spectral analysis of this data series over the same period (1557-1750) shows a non-stationary oscillation, the period of which varied from four to eight years. Figure 2 illustrates this oscillation unfiltered and after filtering (filter window $=3.4-10.6$ years). The cross correlation function between infant mortality and wheat prices shows that the two series synchronise - that is, the maximum cross correlation is obtained at zero lag so that a rise in infant deaths was directly associated with high grain prices.

The hypothesis that high wheat prices caused an increase in infant mortality was tested by the input-output programme. The steady state period, 1557-1812, was divided into four, 50 year periods. The coherence between the two series was highly significant $(p<0.001)$ in the short wavelength bands in all four periods, synchronising at zero lag or at $1+$ years. For example, the coherence during the first hundred years (1557-1656) is illustrated in Figure 3. This period was chosen because it is widely assumed that the effects of famine in northwest England were most pronounced at this time. ${ }^{1011}$ The significance was $\mathrm{p}<0.001$ for four, five, and 10 year wavebands.

Table 1 Age-specific mortality for births 1615-1632

\begin{tabular}{|c|c|c|c|c|c|c|c|c|}
\hline \multirow[t]{2}{*}{ Year } & \multirow[t]{2}{*}{$\begin{array}{l}\text { No of } \\
\text { births }\end{array}$} & \multicolumn{5}{|c|}{$\begin{array}{l}\text { Age specific mortality (\% of births) } \\
\text { expressed by year of birth }\end{array}$} & \multirow{2}{*}{$\begin{array}{l}\text { Wheat } \\
\text { prices } \\
\text { per qtr (sh) }\end{array}$} & \multirow[t]{2}{*}{$\begin{array}{l}\text { Total } \\
\text { deaths }\end{array}$} \\
\hline & & Infant & $1 y$ & $2-5 y$ & $6-15 y$ & $\begin{array}{l}\text { Total, } \\
1-15 y\end{array}$ & & \\
\hline (1) & (2) & (3) & (4) & (5) & (6) & (7) & (8) & (9) \\
\hline $\begin{array}{l}1615 \\
1616 \\
1617 \\
1618 \\
1619 \\
1620 \\
1621 \\
1622 \\
1623 \\
1624 \\
1625 \\
1626 \\
1627 \\
1628 \\
1629 \\
1630 \\
1631 \\
1632\end{array}$ & $\begin{array}{l}52 \\
41 \\
62 \\
48 \\
51 \\
42 \\
54 \\
48 \\
40 \\
40 \\
53 \\
55 \\
68 \\
56 \\
49 \\
50 \\
54 \\
55\end{array}$ & $\begin{array}{l}21 \cdot 2 \\
22 \cdot 0 \\
21 \cdot 0 \\
22 \cdot 9 \\
17 \cdot 6 \\
21 \cdot 4 \\
22 \cdot 2 \\
18 \cdot 8 \\
50 \cdot 0 \\
20 \cdot 0 \\
20 \cdot 8 \\
23 \cdot 6 \\
10 \cdot 3 \\
16 \cdot 1 \\
20 \cdot 4 \\
18 \cdot 0 \\
25 \cdot 9 \\
34 \cdot 5\end{array}$ & $\begin{array}{c}11 \cdot 5 \\
4 \cdot 9 \\
0 \\
4 \cdot 2 \\
3 \cdot 9 \\
2 \cdot 4 \\
1 \cdot 9 \\
16 \cdot 7 \\
2.5 \\
2 \cdot 5 \\
1 \cdot 9 \\
3 \cdot 6 \\
5.9 \\
12.5 \\
4 \cdot 1 \\
2.0 \\
5.6 \\
0\end{array}$ & $\begin{array}{r}7 \cdot 7 \\
2 \cdot 4 \\
8 \cdot 1 \\
14 \cdot 6 \\
9 \cdot 8 \\
11 \cdot 9 \\
3 \cdot 7 \\
4 \cdot 2 \\
0 \\
5 \cdot 0 \\
7 \cdot 5 \\
9 \cdot 1 \\
1 \cdot 5 \\
1 \cdot 8 \\
4 \cdot 1 \\
4 \cdot 0 \\
5 \cdot 6 \\
12 \cdot 7\end{array}$ & $\begin{array}{c}3.8 \\
7.3 \\
4.8 \\
0 \\
3.9 \\
7.1 \\
1.9 \\
6.3 \\
0 \\
2.5 \\
3.8 \\
3.6 \\
1.5 \\
8.9 \\
2.0 \\
2.0 \\
1.9 \\
5.4\end{array}$ & $\begin{array}{r}23.0 \\
14.6 \\
12.9 \\
18 \cdot 8 \\
17.6 \\
21 \cdot 4 \\
7.5 \\
27 \cdot 2 \\
2.5 \\
10 \cdot 0 \\
13 \cdot 2 \\
16.3 \\
8.9 \\
23 \cdot 2 \\
10 \cdot 2 \\
8.0 \\
13 \cdot 1 \\
18 \cdot 1\end{array}$ & $\begin{array}{l}39 \\
40 \\
49 \\
47 \\
35 \\
30 \\
30 \\
59 \\
52 \\
48 \\
52 \\
49 \\
36 \\
28 \\
42 \\
56 \\
68 \\
53\end{array}$ & $\begin{array}{r}35 \\
57 \\
57 \\
46 \\
40 \\
43 \\
50 \\
49 \\
241 \\
39 \\
34 \\
43 \\
20 \\
43 \\
43 \\
37 \\
41 \\
80\end{array}$ \\
\hline $\begin{array}{l}\text { Mean } \\
\text { (SD) }\end{array}$ & $\begin{array}{l}51 \\
(7 \cdot 42)\end{array}$ & & & & & & $\begin{array}{c}45 \cdot 17 \\
(10 \cdot 96)\end{array}$ & $\begin{array}{r}55 \cdot 4 \\
(47.9)\end{array}$ \\
\hline
\end{tabular}

The fate of the children (that is, age at death or surviving) born in each year can be traced along the respective row. qtr = quarter; sh = shilling 


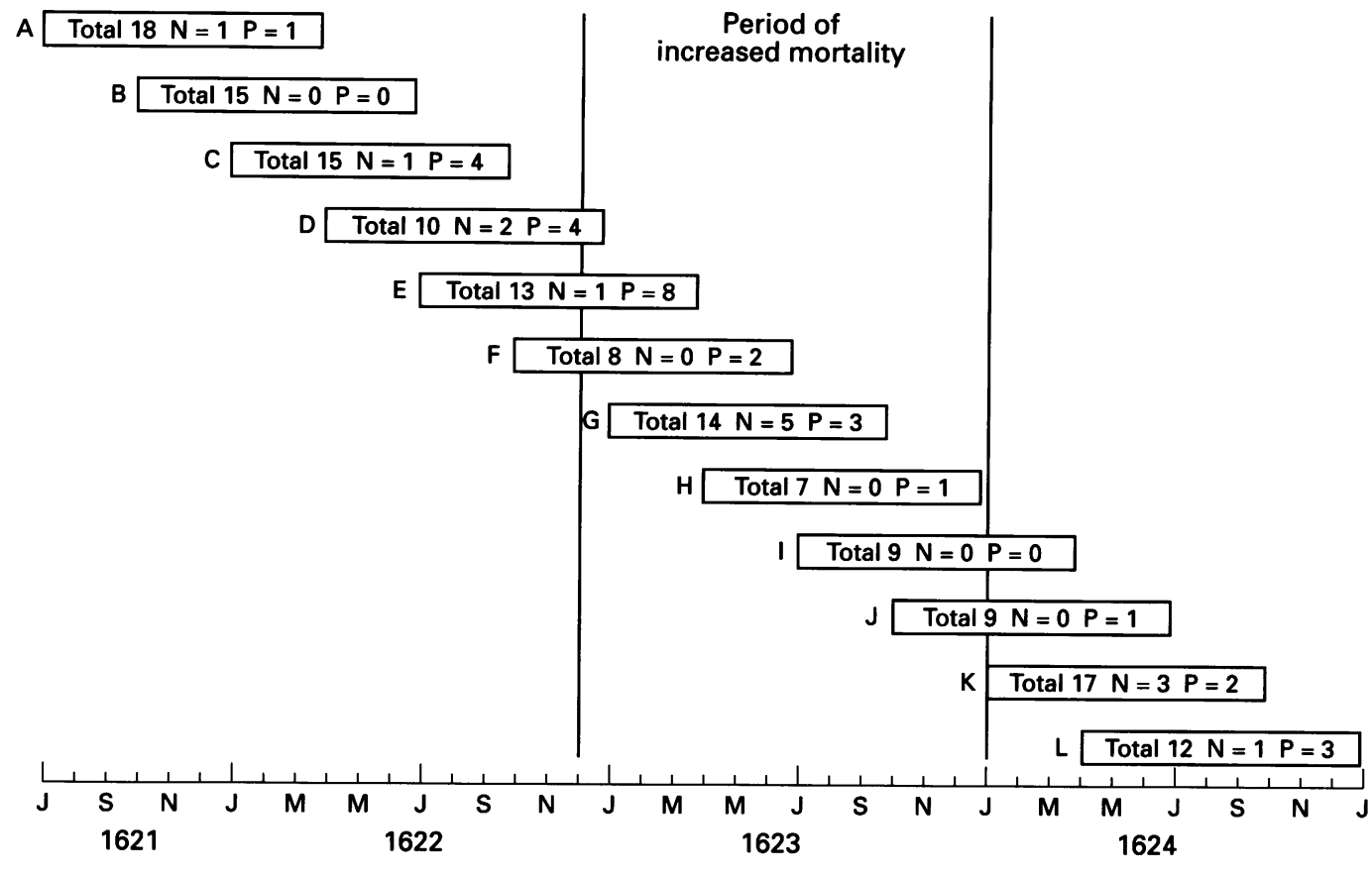

Month conceived

Figure 4 Infant mortality at Penrith between 1621 and 1624 illustrating the effects of the famine of 1623. The births are divided into nine-month cohorts reflecting whether conception and pregnancy occurred before, during, or after the period of famine. The cohorts are separated by three-monthly intervals. Thus, groups $A, B, C, K$, and $L$ are control groups; $D, E$, and $F$ were infants conceived before but born during the famine; $G$ infants were conceived and borm during the famine; $H, I$, and $\mathcal{F}$ were conceived before but born after the famine. The results of the $\chi^{2}$ are tabulated as follows:

\begin{tabular}{lclll}
\hline Groups & Survivors & $\begin{array}{l}\text { Neonate } \\
\text { deaths }\end{array}$ & $\begin{array}{l}\text { Post-neonate } \\
\text { deaths }\end{array}$ & Total \\
\hline ABCKI & 61 & 6 & 10 & 77 \\
DEF & $14^{* *}$ & 3 & $14^{* * *}$ & 31 \\
G & 6 & $5^{* * *}$ & 3 & 14 \\
HIJ & 23 & $0^{* *}$ & 2 & 25 \\
Total & 104 & 14 & 29 & 147 \\
\hline
\end{tabular}

$\chi^{2}=32.4 ; 6$ d.f.; $p<<0.001$. Highly significant $(p<0.001)$ and significant $(p<0.01)$ cells are designated ${ }^{* * *}$ and ${ }^{* *}$ respectively.

ANALYSIS OF THE FAMINE OF 1623

The parish registers at Penrith do not specifically record people dying of famine, but those of the adjacent parish of Greystoke give a description of a particularly severe famine in 1623 , and a number of historical accounts of conditions in Lancashire and Cumbria describe that year as being particularly severe. ${ }^{1025} \mathrm{We}$ have examined the period of 1615-32 at Penrith (that is, 10 years before and after the 1623 famine) in detail and followed the fate of the children born in each year. The results are summarised in table 1 , which shows the age specific mortality of infants and children classified by the year of birth so that it is possible to trace the fates of the children born in each year by following along the respective lines. For example, $21.2 \%$ of the children born in 1615 died as infants, and $11.5 \%$ died as 1 year olds in 1616 . Some $7 \cdot 7 \%$ died between 2 and 5 years of age between 1617 and 1620 (see table 1).

There were 48 births in 1622 (table 1 , column 2), close to the mean annual value of 51 (derived from family reconstitution studies for that period). Although wheat prices (column 8) rose sharply in that year and were high for $1622-23$, infant mortality $(18 \cdot 8 \%$, column 3$)$ remained low. Infant mortality in the following year rose dramatically, however, and $50 \%$ of those born died in the first year of life, but none of those who survived the first year of life died in the parish up to age 15 years. We conclude that the results for 1623 illustrate the deleterious effects of high wheat prices during pregnancy in 1622 which subsequently caused severe infant mortality. High wheat prices also had a direct effect on the mortality of very young children: $16 \cdot 7 \%$ of the children born in 1622 died in their second year of life (column 4) - that is, during the famine of 1623 .

Wheat prices were also very high ( 68 shillings per quarter) in 1631 and total deaths rose to 80 in the following year. Some $34.5 \%$ of those born in 1632 died in infancy (table 1). Conversely 1627-28 was a period of low wheat prices: total mortality was very low whereas births and marriages in the parish were at a peak. Infant mortality (expressed as a percentage of births) was particularly low in 1627 and 1628 (table 1 , column 3 ).

Although poor nutrition during pregnancy was apparently associated with a noticeable increase in infant mortality, columns 4-6 and column 7 in table 1 show that the mortality of the surviving children has little correlation with the annual wheat price index in either the year of their birth or the year preceding their birth. We conclude that table 1 does not provide evidence that famine conditions during pregnancy have indirect effects on the subsequent mortality of the surviving children over the age 


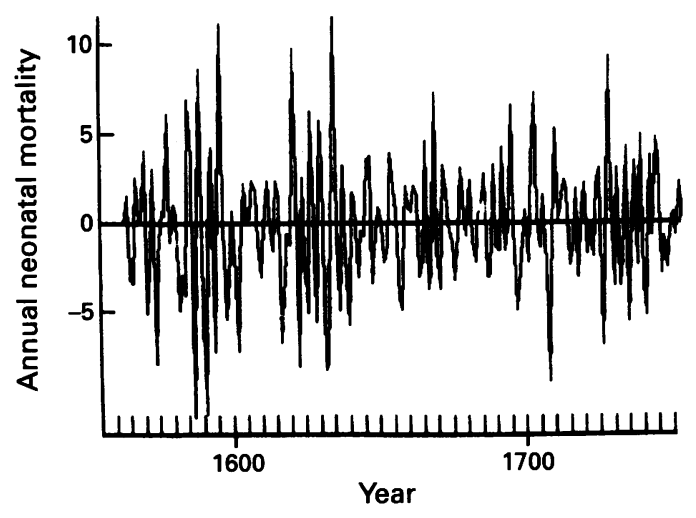

Figure 5 Annual neonatal mortality at Penrith, 1557-1750, expressed as the percentage of births after filtering (ordinate). Filter window $=2 \cdot 5$ to $12 \cdot 8$ years.

of 1 year. However, wheat prices in later years do have a direct effect on childhood mortality. Thus, the high mortality for children at age 1 year for 1622 (table 1, column 4) reflects the high total of 1 year olds who died in the disastrous following year of 1623. The higher values of mortality in the age groups $2-5$ years (column 5) for the children born in the years 1618-20 illustrate how these children were directly affected by the famine conditions of 1622-23 and died then.

THE EFFECTS ON INFANT MORTALITY OF THE FAMINE OF 1623

The records for Penrith for the period 1621-24 have been divided into overlapping nine-month cohorts and the numbers of subsequent neonatal and post-neonatal infant deaths for each group are shown in figure 4 . The cohorts are separated by three-monthly intervals. For example, group $C$ included 15 children who were conceived during the period December 1621 to February 1622 (that is, pre-famine conceptions and birth before there was a noticeable rise in mortality); of these, one child died as a neonate and four as post-neonatal infants. Groups D, $E$, and $F$ children were conceived pre-famine but were exposed to undernutrition and famine conditions during the second and third trimesters of pregnancy. Group $G$ were exposed to famine in utero and after birth, and groups $H, I$, and $J$ were exposed in utero to famine conditions but not after birth. Control groups $A, B, C, K$, and $L$ were either pre-famine conceptions and births or post-famine conceptions and births. It is also evident that the number of baptisms fell considerably during the period of famine. The number in each group is necessarily small but the results provide a significant indication of the effects of malnutrition during pregnancy.

Overall, a highly significant departure from random expectation was established $(p<0.001)$ and three main tendencies become apparent (fig 4). Firstly, groups D, E, and F (conceived before the famine but born when food shortages were acute) displayed a large rise in post-neonatal burials whereas neonatal mortality was not raised. Group $\mathbf{E}$ infants (exposed during the last trimester of pregnancy and then after birth) were the most vulnerable, with the high- est level of post-neonatal mortality. Group D also had a high level of infant mortality with twice as many post-neonates dying as neonates. These fetuses were exposed during the last trimester to conditions that were less severe than the later group.

Secondly, equally significant $(p<0.001)$ are the increased mortality rates as neonatal infants for those conceived and born during the famine (group G). Thirdly, and conversely, the children of the famine (groups $\mathrm{H}, \mathrm{I}$, and J) showed remarkably low infant mortality $(p<0.01)$ and, although the numbers were small, there were no neonatal deaths and only two post-neonatal deaths out of a total of 25 .

NEONATAL AND POST-NEONATAL MORTALITY

The foregoing results suggest that malnutrition may affect neonatal mortality via conditions in pregnancy and also increase post-neonatal mortality directly. The suggestion was tested as follows. Using the family reconstitution data for the period 1557-1750, the annual infant burial records were subdivided into neonatal mortality (28 days post baptisms) and postneonatal mortality (1 to 12 months of life) and the annual mortalities were expressed as a percentage of live births. Spectral analysis showed a complex, non-stationary short wavelength oscillation in both mortality data series which was revealed by filtering (filter window $=$ 2.5 to 12.8 years). The oscillations in neonatal mortality are illustrated in figure 5 . The neonatal and post-neonatal mortality series are strongly coherent in the short wavelength bands $(p<0.001)$. The data series of neonatal and post-neonatal mortality (expressed as a percentage of live births) were then divided into four, 50 year periods (see table 2) and each was run on the input-output (coherence) programme with the wheat price index as input and mortality as output. The results are summarised in table 2, which shows that both mortality series are strongly coherent $(p<0.001)$ with the wheat price index in the short wavelength bands in every cohort. The lag between the neonatal and post-neonatal data series was 0 or +1 years (see table 2 ), with post-neonatal mortality tending towards synchronisation ( 0 years lag) and neonatal mortality showing predominantly a lag of +1 years - that is, peaks of post-neonatal mortality tended to occur in years of high wheat prices whereas high neonatal mortality tended to occur in the year following (when pregnancy occurred during high wheat prices).

AMELIORATION OF POST-NEONATAL MORTALITY Post-neonatal mortality is regarded as being almost entirely attributable to exogenous causes whereas neonatal mortality will include deaths resulting from both endogenous and exogenous causes. ${ }^{26}$ Bourgeois-Pichat ${ }^{27}$ showed that in many populations there is a linear relationship between age and the cumulative infant death rate after the first month of life (postneonatal mortality), when the age is expressed as $[\log (n+1)]^{3}$, where $n$ is age in days since 
Table 2 Coherence between the wheat price index and neonatal or post-neonatal mortalities

\begin{tabular}{|c|c|c|c|c|c|c|c|}
\hline \multirow{2}{*}{\multicolumn{2}{|c|}{ Group }} & \multicolumn{3}{|c|}{$\%$ Neonatal mortality } & \multicolumn{3}{|c|}{$\%$ Post-neonatal mortality } \\
\hline & & \multirow{2}{*}{$\begin{array}{l}\text { Lag } \\
(y)\end{array}$} & \multirow{2}{*}{$\begin{array}{l}\text { Waveband } \\
(y) \\
3-4.5\end{array}$} & \multirow{2}{*}{$\frac{p}{<0.001}$} & \multirow{2}{*}{$\begin{array}{r}\begin{array}{l}\text { Lag } \\
(y)\end{array} \\
0\end{array}$} & $\begin{array}{l}\text { Waveband } \\
y\end{array}$ & $p$ \\
\hline & 1557-1599 & & & & & $\begin{array}{c}3 \cdot 5-4 \\
5-8 \\
10-30\end{array}$ & $\begin{array}{l}<0.01 \\
<0.001 \\
<0.01\end{array}$ \\
\hline $\mathbf{B}$ & $1600-1649$ & +1 & $\begin{array}{l}2 \cdot 5-3 \\
3-3 \cdot 5 \\
5-11\end{array}$ & $\begin{array}{l}<0.001 \\
<0.01 \\
<0.01\end{array}$ & +1 & $\begin{array}{l}10-30 \\
2 \\
3-3 \cdot 7 \\
4 \\
7-11\end{array}$ & $\begin{array}{l}<0.01 \\
<0.001 \\
0.001 \\
<0.01 \\
<0.001\end{array}$ \\
\hline C & $1650-1699$ & 0 & $\begin{array}{l}2 \\
3 \\
7-9\end{array}$ & $\begin{array}{c}<0.001 \\
0.001 \\
0.01\end{array}$ & 0 & $2 \cdot 5-4$ & $<0.001$ \\
\hline D & $1700-1749$ & +1 & $\begin{array}{l}3-4 \\
7-11\end{array}$ & $\begin{array}{r}<0.001 \\
0.001\end{array}$ & 0 & 3 & $<0.01$ \\
\hline
\end{tabular}

Mortality expressed as a percentage of live births in that year. Impulse response function:

\begin{tabular}{|c|c|c|c|c|c|c|}
\hline \multirow[t]{2}{*}{ Group } & \multicolumn{3}{|l|}{$\begin{array}{l}\text { Neonates } \\
\text { lag }(y)\end{array}$} & \multicolumn{3}{|c|}{$\begin{array}{l}\text { Post-neonates } \\
\text { lag }(y)\end{array}$} \\
\hline & 0 & 1 & 2 & 0 & 1 & 2 \\
\hline $\begin{array}{l}\text { A } \\
\text { B } \\
\text { C } \\
\text { D }\end{array}$ & $\begin{array}{c}-0.004 \\
-0.18 \\
0.07 \\
-0.2\end{array}$ & $\begin{array}{c}0.17 \\
0.31 \\
-0.006 \\
0.007\end{array}$ & $\begin{array}{c}0.13 \\
-0.006 \\
0.006 \\
0.0007\end{array}$ & $\begin{array}{c}0.26 \\
-0.008 \\
0.009 \\
0.12\end{array}$ & $\begin{array}{l}0.005 \\
0.28 \\
0.005 \\
-0.16\end{array}$ & $\begin{array}{c}-0.0006 \\
-0.44 \\
-0.2 \\
0.02\end{array}$ \\
\hline
\end{tabular}

birth. The cumulative mortality after the first month is plotted on this logarithmic scale and the calculated regression is extrapolated to age 0 , which is regarded as the estimated true endogenous mortality.

Post-neonatal mortality plotted in this way is shown in figure 6 for the periods 1557-1649 and 1650-1749, together with the period of the population boom, 1750-1812, for comparison. Endogenous (neonatal) mortality fell progressively from $11.7 \%(1557-1649)$ to $8.8 \%$ (1650-1749) to $4.0 \%$ (during the boom 1750 1812). Post-neonatal mortality (shown by the slopes of the lines A and B in fig 6) remained

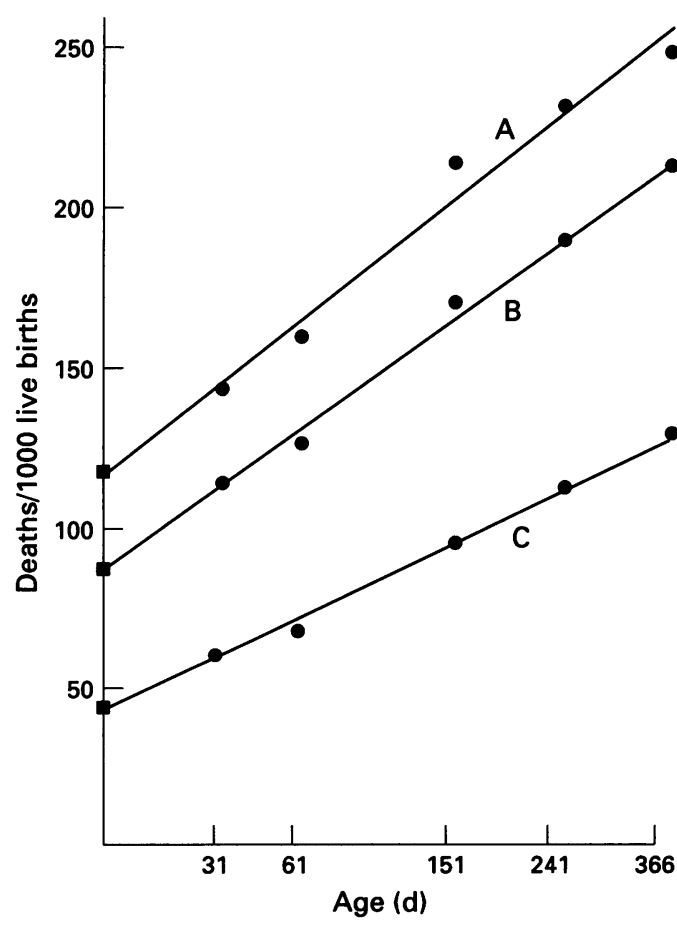

Figure 6 Cumulative infant death rate after the first month of life plotted against age (days) expressed as $[\log (n+1)]^{3}$, where $n=$ age in days. Upper line $(A)$; $1557-1649 ; r=0.986 ; p=0.002 ; a=117, b=8 \cdot 27$. Middle line (B): 1650-1749; $r=0.997 ; p=0.0005 ; a=$ $87 \cdot 5 ; b=7 \cdot 55$. Lower line $(C): 1750-1812 ; r=0.998$; $p=0.005 ; a=40 \cdot 3 ; b=5 \cdot 31$. almost constant during the steady state conditions of 1557-1750. After 1750, however, the density dependent constraints associated with a poor food supply were lifted and figure 6 shows that during this period not only was endogenous mortality clearly reduced (falling by $50 \%$ ) but exogenous mortality also fell (by $33 \%$ ) for the first time.

\section{Conclusions}

We have studied the community at Penrith in detail $^{6-9192022}$ and have shown that it is an example of a small human population living under marginal conditions that was in steady state during 1557-1750, being maintained by density dependent feedback. ${ }^{6}$ This density dependent control was largely determined by famine and hardship; if the population increased in size both infant mortality ${ }^{20}$ and emigration rose. ${ }^{19}$

It is suggested that the community at Penrith is a suitable one to test the thesis that poor nutrition during pregnancy had profound effects on infant mortality and on the health of the surviving children. Infant mortality fluctuated throughout the period of density dependent conditions (1557-1750) and a clear, non-stationary, short wavelength oscillation is found after linear filtering (fig 1). It is suggested that this oscillation is driven by alternating periods of hardship and plenty. Although the main grain crop grown at Penrith during the 17 th century was bigg, barley prices cross correlate at zero lag with the wheat price index and the latter has been used as a measure of fluctuating hardship and famine (fig 2). The non-stationary, short wavelength oscillations in infant mortality and wheat prices index shown by linear filtering (given in figs 1 and 2) synchronise. Furthermore, the coherence between the two series is highly significant $(p<0.001)$. The period around 1622-23, the years of the great famine in northern England, has been examined in greater detail (table 1 and fig 4) and the results illustrate the adverse effects of poor nutrition during pregnancy on subsequent 
infant mortality. A sharply fluctuating food supply could produce another exacerbating effect on infant mortality, particularly in the poorer classes. A large and potentially beneficial placenta could be built up early in pregnancy with good nutrition, but if this were rapidly followed by a drastic reduction in food supply, the large placenta would deprive the developing foetus of adequate nutrition (DJP Barker, personal communication).

Non-stationary, short wavelength oscillations were also shown by linear filtering when infant mortality was subdivided into neonatal (endogenous) and post-neonatal (exogenous) mortality. Both neonatal and post-neonatal mortality were strongly coherent with the wheat price index in the short wavelengths $(p<0.001)$. We conclude that these studies of the population at Penrith, which lived under very difficult conditions and hence was susceptible to fluctuations in the quality and quantity of the food supply, provide supporting historical evidence for the hypothesis that infant mortality is particularly sensitive to poor nutrition of the mother during pregnancy. Table 2 and figure 4 provide tentative evidence that neonatal mortality is related to such endogenous causes as malnutrition during pregnancy (there is a lag of +1 years with the wheat price index), whereas post-neonatal mortality (zero lag with wheat prices) is directly dependent on exogenous causes such as the food supply during the first year of life, which affected both lactation and weaning. Since famine conditions would frequently overlap pregnancy and infancy, however, a clear separation of the lag period for the two components of infant mortality would not be expected.

The conclusions concerning the effects of malnutrition during pregnancy and infancy at Penrith during the 16th, 17th and 18th centuries are, of necessity, based on indirect evidence but they fully support the classic studies in historical epidemiology in the early 20th century by Barker et al..$^{1-5}$ These workers had access to the detailed records of Hertfordshire and have clearly shown that nutrition in pregnancy has a profound effect on neonatal mortality, even though this population was not existing at substistence level (and at times on the edge of starvation) as at Penrith

The famine at Penrith in 1623 can be compared with the Dutch hunger winter between September 1944 and May 1945 when the west Netherlands, under enemy occupation, was exposed to severe famine during a particularly harsh winter. The calorific value of food intake and medical records have been studied in detail and a valuable data base has been assembled. ${ }^{28} 29$ The other regions of the Netherlands acted as controls in these studies. The south was liberated before the end of 1944 and the agricultural north escaped the worst of the food shortages. Before 1944, the population of west Netherlands had a daily ration of 1800 calories which was reduced to 1600 calories by mid-1944 and thereafter it declined progressively to 400 calories in April 1945, although children and expectant and nursing mothers received additional calories. The far reaching effects of this famine have been documented. For example, there was an immediate increase in mortality. The records for the west Netherlands for the period 1943-47 have been divided into the following groups: (i) pre-famine conception and births; (ii) pre-famine conception but exposed to famine during the second and third trimesters of pregnancy; (iii) pre-famine conception, exposed to famine in utero but not after birth; (iv) conceived and exposed in utero to famine conditions but not after birth; and (v) post-famine conception. The cohort exposed during the last trimester of pregnancy and then after birth were the most vulnerable, showing higher levels of neonatal mortality and mortality of liveborn infants. Conversely, the children of the famine who survived infancy did not seem to be at special risk and these authors found that they had better survival during the first two decades of life. Stein $e t a l^{28}$ have identified a daily ration of 1500 calories as the threshold that sustained fecundity in the west Netherlands. Furthermore, the nutritional threshold for conception was clearly lower than the nutritional threshold for fetal viability. It was concluded that famine exerts its greatest effect just before or just after birth, rather than early in the prenatal period. These findings correlate well with the effects of the 1623 famine at Penrith, which are shown diagrammatically in figure 4 . The highest neonatal mortality was recorded in the cohort conceived and born during the famine, whereas the highest post-neonatal mortality was found in cohorts conceived before and born during the famine, particularly those that were exposed to the severest effects of the famine during the last trimester (groups D and E, fig 4).

It is probably unwise to draw general conclusions from the extreme Dutch hunger winter. Some of the potential effects of famine on children may have been mitigated because of the rationing policy that favoured pregnant mothers and young children; the severe famine lasted only seven months and an adequate supply of food was then rapidly re-established. The continuing marginal conditions at Penrith in the 16th and 17th centuries probably mirror more closely those of communities in the Third World today. It was concluded that there was no evidence in the population of west Netherlands for an unequal impact of prenatal famine exposure on mortality by social class, whereas increases in mortality during periods of famine in Bangladesh are highest among the poor of the population, ${ }^{3031}$ probably corresponding to conditions in Penrith. Bangladesh suffered from severe famine in 1974-75 because excessive monsoon flooding destroyed two thirds of the annual rice crop, which, coupled with a poor food distribution system, led to an escalation of the price of rice, increased unemployment, and the erosion of the purchasing power of the poor. This situation corresponds to Penrith where the peaks in the oscillations of the wheat price index cross correlate with falls in the wage index. Again, overall mortality was $62 \%$ higher during the famine in Bangladesh and $31 \%$ higher during the post-famine period than during the non-famine period. 
The effect of the Bangladesh famine has been examined by comparing the mortality rates of three cohorts of children born before, during, and after the famine. ${ }^{31}$ Mortality was higher in those born during the famine up to the second year of life, whereas it was higher only in the first year in those conceived during the famine. Thereafter, mortality in these two cohorts was low and the difference eventually disappeared after the 24th month. Post-neonatal mortality among the poor in the cohort born in the famine was higher than among the better off. Mortality of children of younger mothers (below the age of 20) born and conceived during the famine was particularly high in their second year.

During the density dependent period at Penrith (1550-1750), endogenous mortality fell slightly whereas exogenous mortality remained almost constant (fig 6). On the other hand, endogenous mortality was halved after 1750 during the population boom, and exogenous mortality was also sharply reduced. This improvement and expansion after 1750 probably resulted from improvements in agriculture and transport in Cumberland. ${ }^{32}$ The turnip was introduced as a field crop in 1755, with improved crop rotation and the provision of winter feed as important consequences, so that the autumn slaughter of beasts was unnecessary and milk, butter, and fresh meat became available all the year round. The potato and maize were also introduced, together with manuring and improved drainage. ${ }^{13}$ Together, these measures led to a progressively greater exploitation of the resources of the community, a change in the level of the population that could be sustained, a reduction in infant mortality, and a population boom.

We thank Professor D J P Barker for helpful discussion and suggestions.

1 Barker DJP. The fetal and infant origins of adult disease. London: BMJ Group, 1992.

2 Barker DJP. Fetal growth and adult disease. Br $\mathcal{O}$ Obstet Gynaecol 1992;99:275-82.

3 Barker DJP, Osmond C. Infant mortality, childhood nutrition, and ischaemic heart disease in England and Wales. Lancet 1986; : 1077-81.

4 Barker DJP, Martyn CN. The maternal and fetal origins of cardiovascular disease. $\mathcal{f}$ Epidemiol Community Health $1992 ; 46: 8-11$.
5 Barker DJP, Osmond C, Law CM. The intra-uterine and early postnatal origins of cardiovascular disease and chronic bronchitis. J Epidemiol Community Health 1989 ; 43:237-40.

6 Duncan SR, Scott S, Duncan CJ. Time series analysis of oscillations in a model population: the effects of plague, oscillations in a model population: the effects of plague,

7 Duncan SR, Scott S, Duncan CJ. An hypothesis for the periodicity of smallpox epidemics as revealed by time series analysis. $\mathcal{F}$ Theor Biol 1993;160:231-48.

8 Duncan SR, Scott S, Duncan CJ. The dynamics of smallpox epidemics in Britain, 1550-1800. Demography 1993;30. 405-23.

9 Duncan SR, Scott S, Duncan CJ. Modelling the differen smallpox epidemics in England. Philos Trans R Soc B 1994 346:407-19.

10 Appleby AB. Disease or famine? Mortality in Cumberland and Westmorland. Economic History Review, 1973;xyi: 403-32.

11 Appleby AB. Famine in Tudor and Stuart England Liverpool: Liverpool University Press, 1978.

12 Thirsk J. The farming regions of England. In: Finberg HPR ed. The agrarian history of England and Wales, Vol IV, 1500-1640. Cambridge: Cambridge University Press, 1967:1-109.

13 Bouch CML, Jones GP. The Lake counties 1500-1830. Manchester: Manchester University Press, 1961

14 Hutchinson W. The history of the County of Cumberland. Carlisle: F Jollies, 1794

15 Bailey J, Culley C. General view of the agriculture of the Count of Cumberland, drawn up for the Boards of Agriculture. London, 1794

16 Haswell CS. The registers of St Andrew's Parish Church, Penrith. Vol 1-5. Carlisle: Parish Register Section of the Cum berland and Westmorland Antiquarian Society, 1938.

17 Wrigley EA, ed. An introduction to English historical demography. London: Weidenfeld and Nicholson, 1966.

18 Shumway RH. Applied statistical time series analysis. Wisconsin: Prentice-Hall International Editions, 1988.

19 Duncan SR, Scott S, Duncan CJ. Determination of a feedback vector that generates a non-decaying oscillation in a model population. $\mathcal{f}$ Theoret Biol 1994;167:67-71.

20 Duncan SR, Scott S, Duncan CJ. Predictions from time Duncan SR, Scott $S$, Duncan CJ. Predictions from time
series analysis of the oscillations in parish register series. f Theoret Biol 1994;168:95-103.

21 Wrigley EA, Schofield RS. The population history of England 1541-1871. Cambridge: Cambridge University Press, 1981.

22 Scott S, Duncan CJ. Marital fertility in Penrith, 1557-1812 - evidence for a malnourished community? Transaction of the Cumberland and Westmorland Antiquarian and Archaeological Society (in press).

23 Frisch RE. Population, food intake and fertility. Science, 1978;199:22-30.

24 Stratton JM. Agricultural reconds AD 220-1968. London: John Baker Ltd, 1970.

25 Rogers CD. The Lancashire population crisis of 1623. Manchester, Manchester University Press, 1975.

26 Knodel JE. Demographic behaviour in the past. Cambridge: Cambridge University Press, 1988.

27 Bourgeois-Pichat J. An anaysis of infant mortality. Population Bulletin of the United Nations, 1952;2:1-14.

28 Stein Z, Susser M, Saenger G, Marolla F. Famine and human development: The Dutch hunger winter of 1944-45. Oxford: Oxford University Press, 1975.

29 Hart N. Famine, maternal nutrition and infant mortality: a re-examination of the Dutch hunger winter. Populatio Studies 1993;47:27-46.

30 Watkins SC, Menken J. Famines in historical perspective. Population and Development Review 1985;11:647-75.

31 Razzaque A, Alam N, Wai L, Foster A. Sustained effects of the 1974-5 famine on infant and child mortality in a rural area of Bangladesh. Population Studies 1990;44:145-54.

32 McKeown T. Food, infection and population. fournal of Interdisciplinary History. 1983;14:227-47. 